\title{
Variability of estimated contamination extent depending on calculation methods
}

\author{
Rimantė Zinkutė ${ }^{1}$, Ričardas Taraškevičius ${ }^{1}$, Saulius Gulbinskas ${ }^{2}$, Žilvinas Stankevičius $^{3}$, \\ Margarita Jankauskaite ${ }^{1}$ \\ ${ }^{1}$ Nature Research Centre, Akademijos 2, Vilnius LT-08412, \\ ${ }^{2}$ Open access center for marine research, \\ Klaipeda University, Herkaus Manto 84, Klaipéda LT-92294 \\ ${ }^{3}$ Department of Geology and Mineralogy, \\ Vilnius University, M.K. Čiurlionio 21/27, Vilnius LT-03101
}

\begin{abstract}
The aim of research was to analyse the changes of contamination extent (E, \%) estimated using two methods of background calculation by eliminating anomalies outside the interval mean $\pm 2 \sigma$ or median \pm 2 MAD ( $\sigma$ is standard deviation, MAD is median absolute deviation) and optional normalisation. Two methods were used for estimation of background values (B) and upper threshold values (T) of $\mathrm{Ag}, \mathrm{As}, \mathrm{Ba}, \mathrm{Co}, \mathrm{Cr}, \mathrm{Cu}, \mathrm{Mn}, \mathrm{Mo}, \mathrm{Ni}, \mathrm{Pb}, \mathrm{Sn}, \mathrm{U}$, $\mathrm{V}, \mathrm{Zn}$ and selected major elements according to their contents in topsoil samples from football fields in less contaminated districts of Klaipėda. Then two different sets of $B$ and $T$ values were applied to the whole geochemical data set. After determination of two sets of concentration coefficients $\left(K_{k}\right)$, four sets of enrichment factors were calculated: two simple $\left(\mathrm{EF}_{1}\right)$ (normalisation by $\mathrm{Al}$ ) and two complex $\left(\mathrm{EF}_{3}\right)$ (normalisation by $\left.\mathrm{Al}, \mathrm{K}, \mathrm{Ti}\right)$.

Estimation of $E$ using $T$ values resulted in lower percentage compared to percentage of sites where $K_{k}>1, E_{1}>1$ or $E_{3}>1$, because the latter 3 indices depend on $B$ values. Since all $T$ values obtained by median \pm 2 MAD method are much lower (by 6-37.1\%) than by mean $\pm 2 \sigma$ method, respective $E$ is much higher: for 11 pollutants it is higher by more than 5\% (range 6.3-34.2\%). Since the absolute difference between $B$ values estimated by two methods is much lower (only for $\mathrm{Sn}$ and $\mathrm{Mn}$ exceeds $5 \%$ ) than the difference between $\mathrm{T}$ values, the influence of different $\mathrm{B}$ values on estimated $E$ is much lower. Higher than $5 \%$ absolute difference between two sets of $E$ estimated according to $K_{k}>1$ is observed for 5 pollutants, according to $E F_{3}>1$ for 4 and according to $E F_{1}>1$ only for 3 pollutants. So $E$ estimated according to $E F_{1}>1$ is least of all influenced by the method of determination of $B$ values, besides, it usually gives the highest E.
\end{abstract}

Keywords: background value, concentration coefficient, enrichment factor, upper threshold value.

\section{INTRODUCTION}

Trace element background estimation is one of the fundamental geochemical tasks. It is necessary not only for exploration of mineral resources, but also for assessment of contamination. However, there is no consensus among scientists how to calculate geochemical background in particular area. Different concepts and definitions of the background (natural, ambient, pre-industrial) have been discussed [1], [2]. Some geochemists also use the term "baseline" [3] [5]. It is a sum of background and anthropogenic contribution [5]. Part of researchers [6], [7] consider that the citation of single values for geochemical background is not useful, because background is a range; besides, they are much more concerned about the upper limit of this range, i.e. the upper threshold value $(\mathrm{T})$ and pay less attention to the mean or median values, i.e. the background values $(\mathrm{B})$. The reason is that they rather use $\mathrm{T}$ values for discrimination between the natural and anthropogenic content than calculate various dimensionless indices which depend on $\mathrm{B}$ values and reflect contamination by potentially harmful elements (PHE).

The latter indices are different: contamination factor (CF) used by Hakanson [8], geoaccumulation index (Igeo) defined by Muller [9] and concentration coefficient $\left(\mathrm{K}_{\mathrm{k}}\right)$ [10] are mono-element, meanwhile pollution load index (PLI) [2], enrichment index (EI) [11] and additive contamination index $\left(Z_{d}\right)$ [10] are multi-element. The mentioned indices are without normalisation. The enrichment factor (EF) differs from them, because it is mono-element index which uses normalisation by the content of conservative (or reference) element.

Both $\mathrm{T}$ values and mono-element indices can be used for assessment of topsoil contamination extent (E), i.e. the percentage of samples which are considered as contaminated or possibly contaminated. In both cases, location of sites for background 
estimation and method of background calculation may influence the results. They may also differ depending on whether normalisation was used or not and which reference element was chosen (the magnitude of EF depends on its content and background value).

There is no consensus among scientists concerning the necessity of normalisation. According to Loringh [13] grain size and provenance are the two most significant parameters which must be compensated for by any normalisation procedure. However, according to Reimann and de Caritat [12] the EF (calculated to either the crust or local background) can be high or low due to multitude of reasons, of which contamination is but one; they are influenced by biogeochemical and other near-surface processes. Since the content of usual reference elements is variable in large areas, they state that distribution pattern of EF much more reflects the distribution pattern of the reference elements than anthropogenic contamination. Still soil texture and major soil taxonomical group have a major influence on trace metal concentrations in soil [14]. So it might be useful to carry out normalisation.

There is also no consensus concerning the reference element. Some of the scientists selected Fe as a proxy for clay fraction content [15]. Chang et al. [16] used Cs because its content tends not to be interfered by anthropogenic sources. Loring [13] stated that normalisation by Li may have an universal application to silicate sediments. In ombrotrophic peat bogs cores, usually $\mathrm{Ti}$ is used as conservative element, because its minerals are resistant to chemical weathering [17], sometimes $\mathrm{Zr}$ or Sc [18]. However, the most common element to carry out the normalisation is $\mathrm{Al}$ [19] [21]. Sometimes a group of elements is used for this aim, e.g. median of concentration coefficients of $\mathrm{Al}$, $\mathrm{K}$, Ti [22], because it has been shown that these 3 major elements are good indicators of clay content in urban soil [23].

The methods of geochemical background determination were divided into 3 groups [2]: 1) direct (geochemical) which use either historical or contemporary aspect, 2) indirect (statistical) which are based on spatial analysis or statistical frequency analysis; 3) integrated which combine the first two groups of methods.

Some researchers of soil from natural areas prefer direct historical approach (sometimes integrated with statistical methods), i.e. they presume that soil background concentration can be established from parent material samples (C-horizon) below the level of anthropogenic influence of the same region [15]. They express the level of soil contamination with heavy metals in terms of a distribution index (DI) calculated by dividing metal content in the solum horizon by metal content in parent material. However, Reimann and Garret [1] criticised this approach which can lead to misinterpretations if natural biogeochemical soil processes are ignored.

The most widely used indirect statistical methods are based on the assumption of either normal or lognormal distribution of data, however, regional geochemical data almost never follow these distributions, because they are skewed, have outliers and originate from more than one process [24]. Still in most indirect statistical methods for background determination the researchers have to choose one of the two assumptions.

Eight indirect statistical methods to calculate the background have been reviewed by Matschullat et al.

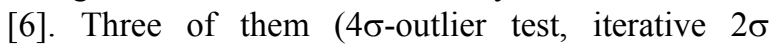
technique ( $\sigma$ is standard deviation) and calculated distribution function method) which are based on presumption of normal distribution were tested by them. The conclusion was done that the second and third methods are appropriate for fast and reliable evaluation of likely $\mathrm{T}$ values. Other five procedures were used by previous researchers and are based on graphical analysis of cumulative frequency distribution curves (CFDC) of either non-transformed or log-transformed data, mode analysis of distribution functions using Al-normalised data or regression technique using conservative element. For regional and local studies with soil samples belonging to both uncontaminated and contaminated populations, the CFDC (using log-transformed data) has shown to be a powerful tool to discriminate different populations of samples and define their background trace element levels [25]. The inflexion points of CFDC that separate different classes in the dataset were identified as the end data points for which the resulting population showed a skewness closest to 0 [26].

Later Reimann et al. [7] compared several procedures for identification of outliers, determination of $\mathrm{B}$ and $\mathrm{T}$ values according to simulated natural (nontransformed) and log-transformed data: 1) mean $\pm 2 \sigma$; 2) boxplot; 3) median \pm 2 MAD (MAD is median absolute deviation); 4) empirical cumulative distribution function.

The aim of the present research was to analyse on example of topsoil from Klaipeda city the variability of estimated contamination extent obtained using two analogous methods of background calculation and optional simple or complex normalisation by selected reference elements.

\section{MATERIALS AND METHODS}

A total of 79 composite topsoil samples was taken in Klaipeda [27]: 51 of them were from the territories of schools and 28 from football fields. Each sample was formed by mixing 20 to 30 sub-samples taken at a depth of $0-10 \mathrm{~cm}$ during zigzag crossing the sampling area of school or football field. The samples were dried and sieved to $<1 \mathrm{~mm}$, then analysed for real total contents of chemical elements. The contents of 12 
PHE (As, Ba, Cr, Cu, Mn, Mo, Ni, Pb, Sn, U, V, Zn) and 3 major elements (Al, K, Ti) were determined by energy-dispersive $\mathrm{x}$-ray fluorescence (EDXRF) equipment Spectro Xepos using TurboQuant for pressed pellets calibration method. The contents of 2 PHE (Ag and Co) were measured by optical atomic emission spectrophotometry (OAES) using spectrograph DFS13.

Basing on previous investigations [27], a subset of 20 football fields which are not in the city centre was chosen for experiments with background estimation, presuming that these sites have only insignificant contamination, though high or low anomalies are possible there. Two methods of elimination of anomalies were applied for the contents of PHE and major elements in this subset. The first method eliminates anomalies outside the interval mean $\pm 2 \sigma$, the second one outside the interval median $\pm 2 \mathrm{MAD}$.

The choice of these methods was determined by their simplicity, lower subjectivity compared to graphical methods of threshold determination and by previous investigations of researchers. Iterative $2 \sigma$ technique (when omitting values outside the range mean $\pm 2 \sigma$ is repeated until all remaining values lie within this range) was tested by Matschullat et al. [6]. It was based on presumption of normal distribution. The procedure similar to iterative mean $\pm 2 \sigma$ was used by Zinkute [28] for log-transformed data; from 6 iterations the version was selected for which the average square deviation of CFDC on the probability paper from the approximating line determined by the least squares method was the lowest.

Both methods selected for experiments were among 4 procedures tested by Reimann et al. [7] according to simulated natural (non-transformed) and logtransformed data. On their opinion, the continued use of the mean $\pm 2 \sigma$ rule is based on misunderstanding and median $\pm 2 \mathrm{MAD}$ procedure is more suitable than mean $\pm 2 \sigma$, but the choice between 3 from 4 tested procedures depends on the percentage of outliers. Besides, on their opinion data should approach a symmetrical distribution before any $\mathrm{T}$ estimations are applied. To find out this, they recommend to calculate the coefficient of variation (CV\%). If $\mathrm{CV}>100 \%$, plots on logarithmic scale should be prepared, if $70 \%<\mathrm{CV}<100 \%$, the inspection of such plots is also informative.

Since the CV values of all PHE in subset from Klaipeda were below $70 \%$, experiments were done only for non-transformed data. Taking into account the above mentioned recommendation not to use iterations, the estimated B (median) and $\mathrm{T}$ values were taken after the first elimination of anomalies. These values were used for calculation of $\mathrm{K}_{\mathrm{k}}$, simple enrichment factor $\left(\mathrm{EF}_{1}\right)\left(\mathrm{K}_{\mathrm{k}}\right.$ of PHE divided by $\mathrm{K}_{\mathrm{k}}$ of $\mathrm{Al})$ and complex enrichment factors $\left(\mathrm{EF}_{3}\right)\left(\mathrm{K}_{\mathrm{k}}\right.$ of PHE divided by the weighted average of $\mathrm{K}_{\mathrm{k}}$ of $\mathrm{Al}, \mathrm{K}$ and $\mathrm{Ti}$ where weights are proportional to the share of their $\mathrm{B}$ values). The values of 3 mono-element indices were used for calculation of respective 3 additive contamination indices $\left(Z_{\mathrm{d}}\right)$.

Then different $\mathrm{B}$ and $\mathrm{T}$ values were applied to the whole data set to find out the contamination extent (E, $\%$ ) by several ways. The first way was to estimate the percentage of sites where the content of PHE exceeds $\mathrm{T}$ (index ET). The second way was to calculate the percentage of sites where $K_{k}>1$ using $B$ values of PHE (index EK). The third and the fourth ways were to calculate the percentage of sites where $E_{1}>1$ (index $\mathrm{EE}_{1}$ ) or $\mathrm{EF}_{3}>1$ (index $\mathrm{EE}_{3}$ ), respectively, using $\mathrm{B}$ values of $\mathrm{PHE}$ and conservative elements.

Median values of the indices and of 3 additive contamination indices gave additional information.

\section{RESULTS AND DISCUSSION}

Though subset used for background estimation was rather homogeneous, anomalies were found for each PHE by both methods (Table I). The mean $\pm 2 \sigma$ method detected only one anomaly for each PHE, it was usually related to high contents, except $\mathrm{Ba}$, Mo and $\mathrm{Mn}$ which had anomalies related to low contents. For all PHE, except As, the median \pm 2 MAD method revealed more anomalies (from 3 to 7), besides, for 8 PHE, the number of high anomalies exceeded the number of low anomalies, for 4 PHE these numbers were the same and only for $\mathrm{Ba}$ and $\mathrm{Ni}$ the number of high anomalies was lower than of low anomalies. The prevalence of high anomalies indicates than the sites selected for background estimation are partly influenced by contamination. However, the fact that for $\mathrm{Ag}, \mathrm{Ni}$ and Mo both estimates of $\mathrm{B}$ values are the same and do not differ from median in subset without any elimination of anomalies points that the influence of pollution on these sites is insignificant.

Due to higher (or at least the same) number of eliminated positive anomalies, the T values of all PHE obtained by median \pm 2 MAD method are much lower (by $6-37.1 \%$ ) than obtained by mean $\pm 2 \sigma$ method, i.e. $\mathrm{T}(2)<\mathrm{T}(1)$. This result corresponds to findings from simulation by Reimann et al. [7] showing that median \pm 2 MAD procedure always results in the lowest $\mathrm{T}$ value, the boxplot in the second lowest and the classical rule mean $\pm 2 \sigma$ in the highest. Earlier results of Matschullat et al. [6] showed that in most cases $4 \sigma-$ outlier test resulted in highest $\mathrm{T}$ values, calculated distribution function method in lower and iterative mean $\pm 2 \sigma$ technique in the lowest $\mathrm{T}$ values. Both $\mathrm{ET}(2)$ and ET(1) values enable to reveal the extent of obvious contamination. Due to lower $\mathrm{T}(2)$ than $\mathrm{T}(1)$, the respective $\mathrm{ET}(2)$ is much higher than $\mathrm{ET}(1)$ estimated according to $\mathrm{T}(1)$ (Table II): for $11 \mathrm{PHE}$ it is higher by more than 5\% (range $6.3-34.2 \%$ ).

So in comparison with many other methods of the background estimation, the median \pm 2 MAD method enables to attribute more sites to the category "contaminated". 
Unlike ET index, the other 3 indices $\left(\mathrm{EK}, \mathrm{EE}_{1}\right.$ and $\left.E_{3}\right)$ which are related to $B$ values enable to reveal the percentage of sites which can be attributed not only to the category "contaminated", but also to category "possibly contaminated" and therefore are much higher than ET percentages. The difference between B values estimated by two methods is much lower (only for $\mathrm{Sn}$ and $\mathrm{Mn}$ exceeds 5\%) than the difference between $\mathrm{T}$ values (Table I). Similarity of medians obtained by both methods does not correspond to the statement of Matschullat et al. [6] that the medians may differ strongly depending on the chosen technique, especially for the mean $\pm 2 \sigma$ approach. The reason of disagreement is that these researchers were comparing mean $\pm 2 \sigma$ approach not with median $\pm 2 \mathrm{MAD}$, but with other methods, besides, their datasets included much more data.

Lower differences between B values explain greater closeness between estimated EK values: $>5 \%$ absolute difference is observed only for 5 PHE (Table II). For $\mathrm{Ag}, \mathrm{As}, \mathrm{Ni}$ and $\mathrm{U}$, the estimated $\mathrm{B}(1)$ and $\mathrm{B}(2)$ values are the same, for $\mathrm{Ba}, \mathrm{Cr}$ and $\mathrm{V}, \mathrm{B}(2)$ values are slightly higher than $\mathrm{B}(1)$, but for other 7 elements they are slightly lower than $\mathrm{B}(1)$. So the median $\pm 2 \mathrm{MAD}$ method shows a tendency to give also lower $B$ values. As a result, $\mathrm{EK}(2)>\mathrm{EK}(1)$ for 7 PHE. However, for 2 PHE (V and $\mathrm{Ba})$, on the contrary, $\mathrm{EK}(2)<\mathrm{EK}(1)$, because due to low anomalies their $\mathrm{B}(2)$ exceeds $\mathrm{B}(1)$.

The values of indices $\mathrm{EE}_{1}$ and $\mathrm{EE}_{3}$ depend on $\mathrm{B}$ values not only of PHE, but also of major elements: $\mathrm{EE}_{1}$ on $\mathrm{Al}, \mathrm{EE}_{3}$ on $\mathrm{Al}, \mathrm{K}$ and $\mathrm{Ti}$. Like for PHE, the mean $\pm 2 \sigma$ method eliminated lower number of their anomalies than median \pm 2 MAD method (Table I). For $\mathrm{Al}$ and $\mathrm{K}$ it has even not found anomalies, so $\mathrm{B}(1)$ values of $\mathrm{Al}$ and $\mathrm{K}$ are the same as in experimental subset. The main feature of major elements is that they have more low anomalies than high anomalies. Therefore elimination of anomalies results in higher $\mathrm{B}(1)$ value of Ti and higher $\mathrm{B}(2)$ values of $\mathrm{Al}, \mathrm{K}$, Ti in comparison with medians in experimental subset.

TABLE I

COMPARISON OF BACKGROUND ESTIMATION RESULTS OBTAINED BY TWO METHODS

NOTES. CHE, CHEMICAL ELEMENT, MED, MEDIAN VALUE (MG/KG) IN SUBSET FOR BACKGROUND ESTIMATION WITHOUT ELIMINATION OF ANOMALIES. PARAMETERS OR THEIR CHANGE: B (MG/KG), BACKGROUND; T (MG/KG), UPPER THRESHOLD; AH, NUMBER OF ELIMINATED HIGH ANOMALIES IN SUBSET; AL, NUMBER OF ELIMINATED LOW ANOMALIES IN SUBSET. THE VALUE IN PARENTHESES: 1, PARAMETER WAS OBTAINED USING MEAN $\pm 2 \sigma$ METHOD; 2 , PARAMETER WAS OBTAINED USING MEDIAN \pm 2 MAD METHOD; \%, THE PERCENTAGE OF THE DIFFERENCE BETWEEN THE VALUE OBTAINED BY MEDIAN \pm 2 MAD METHOD AND BY MEAN $\pm 2 \sigma$ METHOD FROM THE VALUE OBTAINED BY $M E A N ~ \pm 2 \sigma$ METHOD

\begin{tabular}{|c|c|c|c|c|c|c|c|c|c|c|c|}
\hline $\mathrm{ChE}$ & Med & $\mathrm{B}(1)$ & $\mathrm{B}(2)$ & $\mathrm{B}(\%)$ & $\mathrm{T}(1)$ & $\mathrm{T}(2)$ & $\mathrm{T}(\%)$ & $\mathrm{AH}(1)$ & $\operatorname{AL}(1)$ & $\mathrm{AH}(2)$ & $\mathrm{AL}(2)$ \\
\hline $\mathrm{Ag}$ & 0.066 & 0.066 & 0.066 & 0.0 & 0.090 & 0.076 & -16.1 & 1 & 0 & 3 & 2 \\
\hline As & 3.47 & 3.28 & 3.28 & 0.0 & 5.63 & 5.16 & -8.3 & 1 & 0 & 1 & 0 \\
\hline $\mathrm{U}$ & 0.94 & 0.91 & 0.91 & 0.0 & 1.67 & 1.33 & -20.5 & 1 & 0 & 3 & 0 \\
\hline $\mathrm{Ba}$ & 338 & 342 & 345 & 0.8 & 377 & 355 & -6.0 & 0 & 1 & 1 & 6 \\
\hline $\mathrm{V}$ & 28.0 & 26.9 & 28.0 & 4.2 & 42.7 & 38.1 & -10.9 & 1 & 0 & 2 & 2 \\
\hline Mo & 0.68 & 0.68 & 0.68 & -0.3 & 0.79 & 0.73 & -8.0 & 0 & 1 & 3 & 3 \\
\hline $\mathrm{Cu}$ & 11.0 & 10.8 & 10.7 & -0.5 & 16.6 & 12.8 & -23.1 & 1 & 0 & 4 & 1 \\
\hline $\mathrm{Zn}$ & 63.8 & 63.5 & 62.6 & -1.5 & 90.9 & 79.6 & -12.5 & 1 & 0 & 3 & 0 \\
\hline $\mathrm{Mn}$ & 297 & 305 & 289 & -5.2 & 386 & 333 & -13.7 & 0 & 1 & 2 & 1 \\
\hline $\mathrm{Sn}$ & 2.92 & 2.79 & 2.58 & -7.5 & 5.17 & 3.25 & -37.1 & 1 & 0 & 5 & 0 \\
\hline $\mathrm{Al}$ & 34966 & 34966 & 35340 & 1.1 & 45161 & 43895 & -2.8 & 0 & 0 & 0 & 1 \\
\hline $\mathrm{K}$ & 18118 & 18118 & 18309 & 1.1 & 22490 & 21121 & -6.1 & 0 & 0 & 0 & 2 \\
\hline $\mathrm{Ti}$ & 2024 & 2033 & 2033 & 0.0 & 2584 & 2343 & -9.3 & 0 & 1 & 2 & 3 \\
\hline
\end{tabular}


Rimantè Zinkutè, et al./ Environment. Technology. Resources, (2015), Volume II, 337-343

TABLE II

INFLUENCE OF CALCULATION METHOD ON ESTIMATED CONTAMINATION EXTENT

NOTES. PHE, POTENTIALLY HARMFUL ELEMENT; ET, PERCENTAGE OF SITES WHERE THE CONTENT OF PHE EXCEEDS T; EK, PERCENTAGE OF SITES WHERE $\mathrm{K}_{\mathrm{K}}>1 ; \mathrm{EE}_{3}$, PERCENTAGE OF SITES WHERE $\mathrm{EF}_{3}>1 ; \mathrm{EE}_{1}$, PERCENTAGE OF SITES WHERE $\mathrm{EF}_{1}>1$. THE VALUE IN PARENTHESES: 1 , PARAMETER FOR CALCULATION WAS OBTAINED USING MEAN $\pm 2 \sigma$ METHOD; 2 , PARAMETER FOR CALCULATION WAS OBTAINED USING MEDIAN \pm 2 MAD METHOD; D, THE DIFFERENCE BETWEEN THE PERCENTAGE WHEN PARAMETER FOR CALCULATION WAS OBTAINED BY MEDIAN \pm 2 MAD METHOD AND WHEN IT WAS OBTAINED BY MEAN $\pm 2 \sigma$ METHOD.

\begin{tabular}{|l|l|l|l|l|l|l|l|l|l|l|l|l|}
\hline $\mathrm{PHE}$ & $\mathrm{ET}(1)$ & $\mathrm{ET}(2)$ & $\mathrm{ET}(\mathrm{D})$ & $\mathrm{EK}(1)$ & $\mathrm{EK}(2)$ & $\mathrm{EK}(\mathrm{D})$ & $\mathrm{EE}_{3}(1)$ & $\mathrm{EE}_{3}(2)$ & $\mathrm{EE}_{3}(\mathrm{D})$ & $\mathrm{EE}_{1}(1)$ & $\mathrm{EE}_{1}(2)$ & $\mathrm{EE}_{1}(\mathrm{D})$ \\
\hline $\mathrm{Ag}$ & 40.5 & 50.6 & 10.1 & 65.8 & 65.8 & 0.0 & 73.4 & 74.7 & 1.3 & 74.7 & 74.7 & 0.0 \\
\hline $\mathrm{As}$ & 3.8 & 6.3 & 2.5 & 40.5 & 40.5 & 0.0 & 46.8 & 50.6 & 2.5 & 50.6 & 51.9 & 1.3 \\
\hline $\mathrm{Ni}$ & 5.1 & 15.2 & 10.1 & 59.5 & 59.5 & 0.0 & 77.2 & 78.5 & 1.3 & 78.5 & 78.5 & 0.0 \\
\hline $\mathrm{U}$ & 3.8 & 10.1 & 6.3 & 40.5 & 40.5 & 0.0 & 60.8 & 60.8 & 0.0 & 62.0 & 63.3 & 1.3 \\
\hline $\mathrm{Ba}$ & 12.7 & 38.0 & 25.3 & 50.6 & 46.8 & -3.8 & 75.9 & 75.9 & 0.0 & 77.2 & 78.5 & 1.3 \\
\hline $\mathrm{Cr}$ & 30.4 & 32.9 & 2.5 & 57.0 & 57.0 & 0.0 & 65.8 & 65.8 & 0.0 & 68.4 & 68.4 & 0.0 \\
\hline $\mathrm{V}$ & 1.3 & 2.5 & 1.3 & 40.5 & 34.2 & -6.3 & 59.5 & 54.4 & -6.3 & 60.8 & 58.2 & -2.5 \\
\hline $\mathrm{Mo}$ & 16.5 & 30.4 & 13.9 & 43.0 & 45.6 & 2.5 & 70.9 & 70.9 & 0.0 & 69.6 & 72.2 & 2.5 \\
\hline $\mathrm{Cu}$ & 36.7 & 57.0 & 20.3 & 79.7 & 81.0 & 1.3 & 78.5 & 79.7 & 1.3 & 79.7 & 79.7 & 0.0 \\
\hline $\mathrm{Zn}$ & 59.5 & 68.4 & 8.9 & 87.3 & 88.6 & 1.3 & 83.5 & 88.6 & 5.1 & 83.5 & 86.1 & 2.5 \\
\hline $\mathrm{Co}$ & 1.3 & 29.1 & 27.8 & 39.2 & 54.4 & 15.2 & 73.4 & 77.2 & 3.8 & 74.7 & 79.7 & 5.1 \\
\hline $\mathrm{Pb}$ & 40.5 & 74.7 & 34.2 & 82.3 & 88.6 & 6.3 & 83.5 & 86.1 & 2.5 & 83.5 & 86.1 & 2.5 \\
\hline $\mathrm{Mn}$ & 6.3 & 19.0 & 12.7 & 36.7 & 54.4 & 17.7 & 67.1 & 81.0 & 13.9 & 69.6 & 82.3 & 12.7 \\
\hline $\mathrm{Sn}$ & 17.7 & 45.6 & 27.8 & 65.8 & 73.4 & 7.6 & 69.6 & 79.7 & 10.1 & 72.2 & 79.7 & 7.6 \\
\hline
\end{tabular}

Besides, unlike PHE, B(2) values of reference elements are mainly higher (for $\mathrm{Al}$ and $\mathrm{K}$ ) than respective $\mathrm{B}(1)$ values or at least equal to them (for Ti). Higher background of $\mathrm{Al}$ decreases its $K_{k}$, so during normalisation by $\mathrm{Al}$ the $\mathrm{EF}_{1}$ values of PHE can often be higher than respective $K_{k}$ values. This regularity is reflected in median values of respective indices of all PHE (Table III). The $\mathrm{EF}_{3}$ values should also be usually higher than $K_{k}$ values, the explanation is given below. The weights of $\mathrm{K}$ and Ti obtained by both methods are the same $(0.329$ and 0.037 , respectively), of $\mathrm{Al}$ almost the same ( 0.634 by mean $\pm 2 \sigma$ method and 0.635 by median $\pm 2 \mathrm{MAD}$ method). The highest share of $\mathrm{K}_{\mathrm{k}}$ of Al compared to $\mathrm{K}_{\mathrm{k}}$ of other 2 major elements determines the highest influence of its $\mathrm{K}_{\mathrm{k}}$ on the value of $\mathrm{EF}_{3}$. For both methods of background estimation, median values of $\mathrm{EF}_{3}$ of all PHE are higher than median $\mathrm{K}_{\mathrm{k}}$, but lower than median $\mathrm{EF}_{1}$ values (Table III). The median values of additive contamination index $\left(\mathrm{Z}_{\mathrm{d}}\right)$ calculated according to $\mathrm{EF}_{3}$ are also higher than median $Z_{d}$ values calculated according to $K_{k}$, but lower than median $Z_{d}$ values calculated according to $\mathrm{EF}_{1}$ (Fig. 1).

For most PHE, except V, the $\mathrm{EE}_{3}(1)$ and $\mathrm{EE}_{3}(2)$ values are closer to each other than $\operatorname{EK}(1)$ and $\operatorname{EK}(2)$ values, because $>5 \%$ absolute difference is observed only for 4 PHE (Table II). The values of $\mathrm{EE}_{1}(1)$ and $\mathrm{EE}_{1}(2)$ are even closer, because $>5 \%$ absolute difference is observed only for 3 PHE. The tendency of $\mathrm{EE}_{3}(2)>\mathrm{EE}_{3}(1)$ and $\mathrm{EE}_{1}(2)>\mathrm{EE}_{1}(1)$ is observed for 9 $\mathrm{PHE}$, while for $\mathrm{V}$ there is the opposite relationship.
TABLE III

MEDIAN VALUES OF MONO-ELEMENT INDICES IN THE WHOLE DATA SET. NOTES. PHE, POTENTIALLY HARMFUL ELEMENT; VALUE IN PARENTHESES: 1, B VALUES WERE OBTAINED USING MEAN $\pm 2 \sigma$ METHOD; 2 , B VALUES WERE OBTAINED USING MEDIAN \pm 2 MAD METHOD. HIGHER OF TWO VALUES OF EACH INDEX IS IN BOLD.

\begin{tabular}{|l|l|l|l|l|l|l|}
\hline $\mathrm{PHE}$ & $\mathrm{K}_{\mathrm{k}}(1)$ & $\mathrm{EF}_{3}(1)$ & $\mathrm{EF}_{1}(1)$ & $\mathrm{K}_{\mathrm{k}}(2)$ & $\mathrm{EF}_{3}(2)$ & $\mathrm{EF}_{1}(2)$ \\
\hline $\mathrm{Zn}$ & 1.56 & 1.93 & 1.97 & $\mathbf{1 . 5 8}$ & $\mathbf{1 . 9 8}$ & $\mathbf{2 . 0 2}$ \\
\hline $\mathrm{Pb}$ & 1.51 & 1.72 & 1.73 & $\mathbf{1 . 5 8}$ & $\mathbf{1 . 8 2}$ & $\mathbf{1 . 8 3}$ \\
\hline $\mathrm{Cu}$ & 1.30 & 1.44 & 1.49 & 1.30 & $\mathbf{1 . 4 7}$ & $\mathbf{1 . 5 1}$ \\
\hline $\mathrm{Ag}$ & 1.18 & 1.32 & 1.33 & 1.18 & $\mathbf{1 . 3 3}$ & $\mathbf{1 . 3 5}$ \\
\hline $\mathrm{Sn}$ & 1.13 & 1.17 & 1.22 & $\mathbf{1 . 2 2}$ & $\mathbf{1 . 2 7}$ & $\mathbf{1 . 3 3}$ \\
\hline $\mathrm{Ni}$ & 1.05 & 1.14 & 1.18 & 1.05 & $\mathbf{1 . 1 5}$ & $\mathbf{1 . 1 9}$ \\
\hline $\mathrm{Co}$ & 0.99 & 1.10 & 1.13 & $\mathbf{1 . 0 1}$ & $\mathbf{1 . 1 3}$ & $\mathbf{1 . 1 6}$ \\
\hline $\mathrm{Cr}$ & $\mathbf{1 . 0 6}$ & 1.10 & 1.11 & 1.05 & 1.10 & $\mathbf{1 . 1 2}$ \\
\hline $\mathrm{Mo}$ & 0.98 & 1.10 & 1.13 & 0.98 & $\mathbf{1 . 1 1}$ & $\mathbf{1 . 1 4}$ \\
\hline $\mathrm{Ba}$ & $\mathbf{1 . 0 0}$ & 1.10 & 1.15 & 0.99 & 1.10 & 1.15 \\
\hline $\mathrm{Mn}$ & 0.96 & 1.07 & 1.11 & $\mathbf{1 . 0 2}$ & $\mathbf{1 . 1 5}$ & $\mathbf{1 . 1 8}$ \\
\hline $\mathrm{U}$ & 0.94 & 1.07 & 1.10 & 0.94 & $\mathbf{1 . 0 8}$ & $\mathbf{1 . 1 1}$ \\
\hline $\mathrm{V}$ & $\mathbf{0 . 9 7}$ & $\mathbf{1 . 0 6}$ & $\mathbf{1 . 0 7}$ & 0.93 & 1.02 & 1.04 \\
\hline $\mathrm{As}$ & 0.89 & 0.99 & 1.02 & 0.89 & $\mathbf{1 . 0 0}$ & $\mathbf{1 . 0 3}$ \\
\hline
\end{tabular}

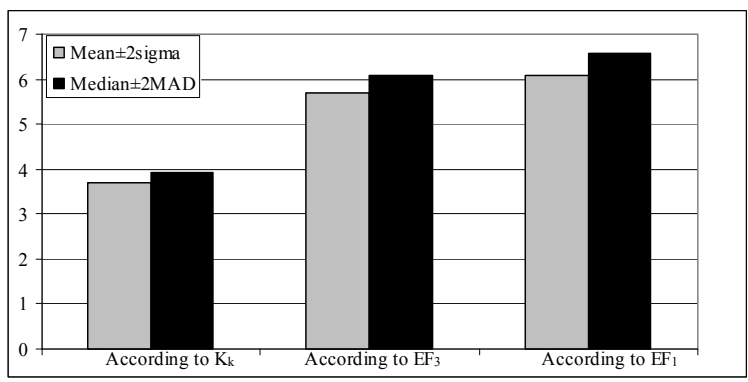

Fig. 1. Median values of the additive contamination index calculated according to different mono-element indices of Ag, As, $\mathrm{Ba}, \mathrm{Co}, \mathrm{Cr}, \mathrm{Cu}, \mathrm{Mn}, \mathrm{Mo}, \mathrm{Ni}, \mathrm{Pb}, \mathrm{Sn}, \mathrm{U}, \mathrm{V}, \mathrm{Zn}$ 


\section{CONCLUSIONS}

The method of background calculation (either mean $\pm 2 \sigma$ or median $\pm 2 M A D$ ) most of all influences the contamination extent which is estimated according to the upper threshold values ( $\mathrm{T}$ ) and reveals the percentage of contaminated sites. The median $\pm 2 \mathrm{MAD}$ gives much lower $T$ values compared to mean $\pm 2 \sigma$ method and many other methods, so for most potentially harmful elements (PHE) it results in much higher (by $>5 \%$ ) percentage of contaminated sites.

The method of background calculation has much lower influence on contamination extent which reflects the joint percentage of contaminated and possibly contaminated sites and which is estimated according to higher than unit mono-element indices: concentration coefficients $\left(\mathrm{K}_{\mathrm{k}}\right)$, simple enrichment factors $\left(E_{1}\right)$ or complex enrichment factors $\left(E_{3}\right)$. The reason is that these indices depend on the background values (B) which differ less than $T$ values. According to decreasing influence of the method of background calculation on the estimated contamination extent the mono-element indices can be arranged as follows: $\mathrm{K}_{\mathrm{k}}, \mathrm{EF}_{3}, \mathrm{EF}_{1}$.

Optional normalisation has much higher influence on the contamination extent than the method of background calculation. Normalisation usually increases the values of mono-element indices and enables to better reveal the areas presumably affected by pollution sources. The results partly depend on the choice of the reference elements. The arrangement of mono-element indices according to increase of the estimated contamination extent is as follows: $\mathrm{K}_{\mathrm{k}}, \mathrm{EF}_{3}$, $\mathrm{EF}_{1}$. The same arrangement is according to increase of the median values of mono-element indices and median values of multi-element additive contamination indices calculated by summing up respective mono-element indices.

\section{REFERENCES}

[1] C. Reimann and R. Garrett, "Geochemical background concept and reality", Science of the Total Environment, vol. 350, pp. 12-27, Nov. 2005.

[2] A. Gałuszka and Z. M. Migaszewski, "Geochemical background - an environmental perspective", Mineralogia, vol. 42, no. 1, pp. 7-17, 2011.

[3] A. G. Darnley, A. Björklund, B. Bølviken, N. Gustavsson, P. V. Koval, J. A. Plant, A. Steenfelt, M. Tauchid and Xie Xuejing, with contributions by R. G. Garrett and G. E. M. Hall, "A global geochemical database for environmental and resource management", Earth Science Series, vol. 19, Paris, France7 UNESCO, 1995.

[4] R. Salminen and V. Gregorauskienè, "Considerations regarding the definition of a geochemical baseline of elements in the surficial materials in areas differing in basic geology", Applied Geochemistry, vol. 15, pp. 647-653, June, 2000.

[5] T C. C. Johnson and A. Demetriades, "Urban geochemical mapping: a review of case studies in this volume", in Mapping the Chemical Environment of Urban Areas, C. C. Johnson, A Demetriades, J. Locutura and R. T. Ottesen, Eds, Chichester: Wiley-Blackwell, 2011, pp. 7-27.
[6] J. Matchullat, R. Ottesen and C. Reimann, "Geochemical background - can we calculate it?", Environmental geology, vol. 39, no. 9, pp. 990-1000, July, 2000.

[7] C. Reimann, P. Filzmoser and R. G. Garrett, "Background and threshold: critical comparison of methods of determination", Science of the Total Environment, vol. 346, pp. 1-16, June, 2005.

[8] L. Håkanson, "Ecological risk index for aquatic pollution control. A sedimentological approach", Water research, vol. 14, issue 8, pp. 975-1001, Aug. 1980.

[9] G. Muller, "Index of geoaccumulation in sediments of the Rhine River", Geojournal, vol. 2, pp. 108-118, 1969.

[10] A V. Gregorauskienè, R. Taraškevičius, V. Kadūnas, A. Radzevičius and R. Zinkutè, "Geochemical characteristics of Lithuanian urban areas", in Mapping the Chemical Environment of Urban Areas, C. C. Johnson, A. Demetriades, J. Locutura and R. T. Ottesen, Eds, Chichester: WileyBlackwell, 2011, pp. 393-409.

[11] L. Bityukova and M. Birke, "Urban geochemistry of Tallinn (Estonia): major and trace-elements distribution in topsoil", in Mapping the Chemical Environment of Urban Areas, C. C. Johnson, A. Demetriades, J. Locutura and R. T. Ottesen, Eds, Chichester: Wiley-Blackwell, 2011, pp. 348-363.

[12] C. Reimann and P. de Caritat, "Distinguishing between natural and anthropogenic sources for elements in the environment: regional geochemical surveys versus enrichment factors", Science of the Total Environment, vol. 337, pp. 91-107, Jan. 2005.

[13] D. H. Loring, "Normalization of heavy-metal data from estuarine and coastal sediments", ICES Journal of Marine Science, vol. 48, issue 1, pp. 101-115, May 1990.

[14] F. J. Zhao, S. P. McGrath and G. Merrington, "Estimates of ambient background concentrations of trace metals in soils for risk assessment", Environmental Pollution, vol. 148, pp. 221229, July, 2009

[15] M. Kobierski and H. Dąbkowska-Naskręt, "Local background concentration of heavy metals in various soil types formed from glacial till of the Inowrocławska plain", Journal of Elementology, vol. 17, no. 4, pp. 559-585, Dec. 2012.

[16] M.-L. Chang, Y.-C. Sun, R.-A. Doong, S.-C. Wu and C.T. Fu, "Concentrations and correlations of trace metals in estuarine sediments - interpretation by multivariate statistical analysis and elemental normalization", J. Environ. Eng. Manage., vol. 17, no. 2, 143-150, 2007.

[17] A. Cheburkin and W. Shotyk, "Energy-dispersive XRF spectrometer for $\mathrm{Ti}$ determination (TITAN)", X-ray Spectrometry, vol. 34, pp. 69-72, Jan./Febr. 2005.

[18] W. Shotyk, P. Blaser, A. Grünig and A. K. Cheburkin, "A new approach for quantifying cumulative, anthropogenic, atmospheric lead deposition using peat cores from bogs: $\mathrm{Pb}$ in eight Swiss peat bog profiles", The Science of the Total Environment, vol. 249, pp. 281-295, April 2000.

[19] A. D. Anbar, Y. Duan, T. W. Lyons, G. L. Arnold, B. Kendall, R. A. Creaser, A. J. Kaufman, G. W. Gordon, C. Scott, J. Garvin and R. Buick, "A whiff of oxygen before the great oxidation event?", Science, vol. 317, pp. 1903-1906, Sept. 2007.

[20] J. Ebbing, J. Zachowicz, S. Uśscinowicz and C. Laban, "Normalisation as a tool for environmental impact studies: the Gulf of Gdansk as a case study", Baltica, vol. 15, pp. 49-62, 2002 .

[21] B. Rubio, M. A. Nombela and F. Vilas, "Geochemistry of major and trace elements in sediments of the Ria de Vigo (NW Spain): an assessment of metal pollution", Marine Pollution Bulletin, vol. 40, no. 11, pp. 968-980, Nov. 2000.

[22] R. Taraškevičius, R. Zinkutė, G. J. Čyžius, M. Kaminskas and M. Jankauskaite, "Soil contamination in one of preschools influenced by metal working industry", in Environment, Technology, Resources: Proceedings of the $9^{\text {th }}$ International Scientific and Practical Conference, June 20-22, 2013, Rezekne, vol. I (Environmental Protection and Monitoring), pp. 83-86, 2013. 
[23] R. Zinkute, R. Taraškevičius and T. Želvys, "Major elements as possible factors of trace element urban pedochemical anomalies", Central European Journal of Chemistry, vol. 9, no. 2, pp. 337-347, April 2011.

[24] C. Reimann and P. Filzmoser, "Normal and lognormal data distribution in geochemistry: death of a myth. Consequences for the statistical treatment of geochemical and environmental data", Environmental geology, vol. 39, no. 9, pp. 1001-1014, Aug. 1999.

[25] M. Díez, M. Simón, F. Martín, C. Dorronsoro, I. García and C. A. M. Van Gestel, "Ambient trace element background concentrations in soils and their use in risk assessment", Science of the Total Environment, vol. 407, iss. 16, pp. 46224632, Aug. 2009.
[26] H. L. Fleischhauer and N. Korte, "Formulation of cleanup standards for trace elements with probability plots", Environmental Management, vol. 14, no. 1, pp. 95-105, Jan. 1990.

[27] R. Taraškevičius and S. Gulbinskas, "Pedogeochemical accumulating associations of education and learning institutions and sport stadiums in Klaipedda", in Proceedings of the $15^{\text {th }}$ International Conference on Heavy Metals in the Environment, September19-23, 2010, Gdansk, Poland, pp. 781-784, 2010

[28] R. Zinkute, Trace Element Technogenous Associations in Urbanised Territories of Lithuania. Vilnius: Institute of Geology and Geography, 2002, 200 p. 